\title{
Psychobiological problems in heavy 'ecstasy' (MDMA) polydrug users
}

\author{
A.C. Parrott *, E. Sisk, J.J.D. Turner \\ Department of Psychology, University of East London, London E15 4LZ, UK
}

Received 14 July 1999; received in revised form 19 November 1999; accepted 22 November 1999

\begin{abstract}
Twelve heavy recreational ecstasy drug users (30-1000 occasions), 16 light ecstasy users (1-20 occasions) and 22 non ecstasy user controls, with group mean ages around 21 years, were compared. Three self-rating questionnaires were completed when drug-free: the SCL-90 (an outpatient psychiatric symptom checklist), the impulsiveness venturesomeness and empathy (IVE) scale; and the uplifts, hassles, stresses and cognitive failures questionnaire. Heavy Ecstasy users reported significantly higher scores than controls on the following SCL-90 factors: paranoid ideation, psychoticism, somatisation, obsessionality, anxiety, hostility, phobic anxiety, altered appetite and restless sleep, together with greater IVE impulsiveness. Light ecstasy users generally produced intermediate scores, with significantly higher scores than controls on two factors and significantly lower scores than heavy ecstasy users on another two. Previous reports have described various psychiatric and psychobiological disorders in recreational ecstasy users, but it is not known how typical they are, being mainly based on individual case studies. This is the first study to describe psychological problems in a non clinical sample of young recreational ecstasy users. However, our ecstasy users were polydrug users, with both groups showing significantly greater usage of amphetamine, LSD and cocaine, than the controls. These other illicit drugs probably contributed to their adverse psychobiological profiles, while there is also the possibility of pre-existing differences between ecstasy users and non users. However, since repeated MDMA can cause serotonergic neurotoxicity in laboratory animals and man, these problems may reflect reduced serotonin activity induced by regular ecstasy use. (C) 2000 Elsevier Science Ireland Ltd. All rights reserved.
\end{abstract}

Keywords: MDMA; Ecstasy; Serotonin; Impulsivity; Paranoia; Psychosis; Psychobiology; Psychiatry; Neurotoxin

\section{Introduction}

MDMA (3,4-methylenedioxymethamphetamine) or 'ecstasy', is used as a recreational drug in many westernized countries. Saunders (1995) estimated that half a million ecstasy tablets are taken each weekend in the UK, while a formal survey of British undergraduates found that $13 \%$ admitted having taken it (Webb et al., 1996). This widespread popularity has given rise to a number of concerns, since laboratory animal research has shown that repeated doses can lead to serotonergic neurodegeneration (Ricaurte et al., 1992; Steele et al., 1994; Green et al., 1995). This neurodegeneration is quite prolonged, although some recovery does generally

\footnotetext{
* Corresponding author. Tel.: + 44-181-5907000 ext 4505; fax: +44-181-8493697.

E-mail address: andy2@uel.ac.uk (A.C. Parrott)
}

occur over time (Steele et al., 1994; Green et al., 1995; Ricaurte et al., in press). The laboratory animal data often involves high doses of MDMA, although Ricaurte et al. (in press) have shown that the dose levels which cause neurodegeneration in laboratory rats, guinea pigs, marmosets and monkeys, are within the range used by young people (based upon standard formulae for inter-species scaling).

There is an increasing body of empirical evidence that MDMA may also be neurotoxic in humans. Drugfree ecstasy users have been shown to display low levels of serotonin and its metabolite 5-HIAA, while neuroimaging, using PET scans has shown a significant reduction in 5-HT transporter binding, with the amount of decrease correlating positively with the extent of prior ecstasy use (McCann et al., 1998; in press). Drug-free, recreational ecstasy users have also shown selective deficits in memory and higher cognitive pro- 
cessing (Krystal et al., 1992; Steele et al., 1994; Morgan, 1998, 1999; Parrott, 1998). There are also indications of psychiatric and/or psychobiological problems, including depression, obsessive-compulsive disorder, paranoia, poor appetite and altered sleep (McCann et al., 1996; Schifano et al., 1998). However, since this evidence generally comes from individual case studies, it is not known how typical or characteristic they are. The current study was designed to compare the psychiatric and psychobiological profiles of three non clinical groups of young people: light recreational ecstasy users, heavy ecstasy users and non user controls.

\section{Method}

\subsection{Subjects}

The participants lived in a small town near Cork in Ireland, where there was an active youth subculture for recreational drug use - particularly ecstasy. The unpaid volunteers were obtained using the 'snowball' technique, originally developed for illicit drug research (Solowij et al., 1992; Davison and Parrott, 1997). The main data collector (ES) informed friends and colleagues about the study and they spread word of it amongst their acquaintances. Every participant completed a questionnaire about their past drug use. It comprised a list of legal and illicit recreational drugs, which they indicated having used or not used (Table 1). Regular ecstasy users were defined as those who stated that they had taken it on more than 20 occasions; the overall mean for this group being 371 times (range
$30-1000$ ). Light ecstasy users were defined as those who had taken it on 20 or less occasions; the overall mean being 6.8 times (range 1-20). The non users (ie. non ecstasy user controls) comprised those who had never taken ecstasy. Nearly everyone used alcohol and cannabis (Table 1), while significantly more ecstasy users were cigarette smokers (Table 1). The main differences between groups, were the significantly higher proportions of light and heavy ecstasy users, who had taken CNS stimulants such as cocaine and amphetamine and/or hallucinogens such as LSD and magic mushrooms, compared to the controls (Table 1). There were no significant differences in age or gender across groups (Table 1).

\subsection{Assessment measures}

The SCL-90 is a clinical symptom self-rating scale, originally designed for use with psychiatric outpatients (Derogatis, 1997). It comprises a list of 90 symptoms, which factorize into a number of psychiatric and psychobiological dimensions: depression, anxiety, somatisation, obsessive-compulsive behaviour, interpersonal sensitivity, hostility, phobic anxiety, psychoticism, paranoid ideation and altered appetite and disturbed sleep. Some sample questions are as follows: 'feeling easily annoyed or irritated' (anger-hostility subscale), 'Having to avoid certain things, places or activities, because they frighten you' (phobic-anxiety subscale) and 'feelings of worthlessness' (depression subscale). Each question had four possible responses: not at all (0); a little bit (1); quite a bit (2); moderately (3); or extremely (4). The number of questions in each factor varied; for

Table 1

Group characteristics and self-reported recreational drug use ${ }^{a}$

\begin{tabular}{lccccc}
\hline & $\begin{array}{l}\text { Non user } \\
\text { controls }\end{array}$ & $\begin{array}{l}\text { Light MDMA } \\
\text { users }\end{array}$ & $\begin{array}{l}\text { Heavy MDMA } \\
\text { users }\end{array}$ & Overall group differences & Paired group comparisons \\
\hline Age & $23.2 \pm 4.9$ & $20.9 \pm 1.6$ & $20.8 \pm 2.2$ & - & - \\
$n$ & 22 & 16 & 12 & - & - \\
Gen (M/F/undeclared) & $11 / 10 / 1$ & $6 / 10$ & $7 / 4 / 1$ & - & - \\
Alcohol & $100 \%$ & $100 \%$ & $92 \%$ & - & NvL, NvH \\
Tobacco & $50 \%$ & $82 \%$ & $92 \%$ & - & NvL, NvH \\
Cannabis & $82 \%$ & $87 \%$ & $100 \%$ & NvL, NvH \\
Amphetamine & $36 \%$ & $69 \%$ & $83 \%$ & $*$ & $\mathrm{NvL,} \mathrm{NvH}$ \\
Cocaine & $14 \%$ & $56 \%$ & $75 \%$ & $* *$ & $\mathrm{NvH,} \mathrm{LvH}$ \\
LSD & $18 \%$ & $69 \%$ & $83 \%$ & - & - \\
Magic mushroom & $27 \%$ & $31 \%$ & $75 \%$ & - & - \\
Barbiturate/Benzodiazepine & $0 \%$ & $12 \%$ & $33 \%$ & - & - \\
Opiate & $14 \%$ & $25 \%$ & $25 \%$ & - & $\mathrm{NvH}$ \\
Anabolic steroid & $5 \%$ & $0 \%$ & $50 \%$ & & \\
Solvents & $14 \%$ & $31 \%$ & &
\end{tabular}

\footnotetext{
a Two-tailed $\chi^{2}$ test (paired group comparisons $\chi^{2}$ at $P<0.05$ level).

* $P<0.05 ; * * P<0.01$.

*** $P<0.001$.
} 
Table 2

Group mean scores $\left( \pm\right.$ S.D.) for the SCL-90, IVE and UPLITS/HASSLES, questionnaires ${ }^{\mathrm{a}}$

Non user controls Light MDMA users Heavy MDMA users

$(N)$
$(H)$
ANOVA group

effect
Tukey paired

comparisons
SCL-90

Somatisation

Obsessionality

Sensitivity

Depression

Anxiety

Hostility

Phobic anxiety

Paranoid-ideation

Psychoticism

Appetite

Overeating

Insomnia

Early waking

Restless sleep

Death cognitions

Guilt

IVE questionnaire

Impulsiveness

Venturesomeness

Empathy
$7.4 \pm 6.1$
$7.4 \pm 5.8$

$6.3 \pm 5.3$

$10.5 \pm 9.1$

$4.9 \pm 4.2$

$3.5 \pm 4.5$

$1.4 \pm 1.9$

$3.4 \pm 4.1$

$3.5 \pm 4.2$

$0.5 \pm 0.9$

$0.7 \pm 1.1$

$1.0 \pm 1.1$

$0.7 \pm 1.0$

$0.8 \pm 1.0$

$0.8 \pm 1.4$

$0.7 \pm 0.9$

$$
\begin{aligned}
& 8.9 \pm 4.7 \\
& 10.4 \pm 3.6 \\
& 11.8 \pm 3.7
\end{aligned}
$$

Uplifts

Hassles

Stresses

Cognitive failures
$11.7 \pm 2.4$

$7.1 \pm 2.6$

$7.1 \pm 3.3$

$6.2 \pm 3.8$

$11.7 \pm 7.4$
$10.6 \pm 8.1$
$11.2 \pm 7.8$
$16.0 \pm 11.4$
$7.5 \pm 7.2$
$6.4 \pm 5.4$
$3.4 \pm 4.3$
$7.4 \pm 5.6$
$9.0 \pm 8.4$
$0.7 \pm 0.9$
$0.7 \pm 1.1$
$1.4 \pm 1.4$
$0.9 \pm 1.3$
$0.9 \pm 1.3$
$1.2 \pm 1.4$
$1.0 \pm 1.2$

$11.1 \pm 4.7$

$11.3 \pm 2.9$

$13.7 \pm 2.9$

$10.0 \pm 3.4$

$8.4+3.5$

$8.2 \pm 4.7$

$7.4 \pm 3.6$

$$
\begin{aligned}
& 15.3 \pm 11.5 \\
& 15.6 \pm 8.5 \\
& 12.2 \pm 8.5 \\
& 16.4 \pm 10.6 . \\
& 13.8 \pm 9.8 \\
& 9.7 \pm 6.7 \\
& 5.0 \pm 5.3 \\
& 9.0 \pm 4.8 \\
& 12.7 \pm 8.3 \\
& 1.7 \pm 1.5 \\
& 0.7 \pm 1.1 \\
& 1.9 \pm 1.0 \\
& 1.7 \pm 1.7 \\
& 1.7 \pm 1.7 \\
& 0.8 \pm 1.3 \\
& 1.3 \pm 1.1
\end{aligned}
$$

$13.4 \pm 3.4$

$10.7 \pm 3.1$

$11.2 \pm 4.2$

$10.4 \pm 3.0$

$6.6 \pm 2.9$

$7.7 \pm 4.8$

$8.3 \pm 3.6$

a All Tukey comparisons; $P<0.05$ (two-tailed) ANOVA.

$* P<0.05$.

** $P<0.01 ; * * * P<0.001$.

instance, the depression subscale had 13 questions, while interpersonal sensitivity had nine (Derogatis, 1997). The SCL-90 questionnaire was selected because it covers the main psychiatric and psychobiological dimensions of interest, is readily completed by normal volunteers and has been successfully used with recreational drug users (Kokkevi et al., 1998).

The impulsiveness, venturesomeness and empathy (IVE) questionnaire comprises 54 self-rating items (Eysenck and Eysenck, 1991) and has been previously used with ecstasy users (Morgan, 1998; Turner et al., unpublished). The uplifts, hassles, stresses and cognitive failures questionnaire, comprised 20 questions, five for each of the four factors. The relative frequency of various types of everyday occurrence (uplifts, hassles, stresses, cognitive failures) over the past month, was self-rated using a four-point response scale: never (0); rarely (1); sometimes (2); or often (3). This questionnaire has been shown to be sensitive to the effects of cigarette smoking and nicotine deprivation (Parrott and
Kaye, 1999). These three questionnaires were completed on a day when the participant was drug-free.

\subsection{Statistical analysis}

All analyses were carried out using SPSS for windows. The questionnaire data was analyzed using oneway ANOVA, with subgroup as the main factor; two-tailed significance values $(P<0.05, P<01$, or $P<$ $0.001)$ are presented. Paired comparisons between groups were calculated using Tukey tests, at the $P$ $<0.05$ level (two-tailed).

\section{Results}

The group mean scores for the SCL-90 questionnaire, IVE questionnaire and uplifts, hassles, stresses and cognitive failures questionnaire, are shown in Table 2, together with the ANOVA and Tukey test findings. 


\section{Discussion}

The heavy ecstasy users displayed a range of psychobiological problems. Compared to non ecstasy user controls, they reported significantly higher scores on the SCL-90 factors for somatisation, obsessionality, anxiety, hostility, phobic-anxiety, paranoid ideation, psychoticism, poor appetite and restless/disturbed sleep (Table 2). These findings agree with previous case studies, where a range of psychiatric and psychobiological problems have been described in recreational MDMA users: psychotic breakdown, paranoia, depression, panic disorder and various eating disorders (McCann and Ricaurte, 1991; Pallanti and Mazzi, 1992; Schifano and Magni, 1994; McCann et al., 1996; Curran and Travill, 1997; Parrott and Lasky, 1998; Series et al., 1994; Turner et al., 1998). Similar types of problem were noted in a survey of ecstasy users attending an Italian drug addiction clinic, where heavy users presented with a range of DSM-11l-R disorders: 'depression, psychotic disorders, cognitive disturbances, bulimic episodes, impulse control disorders, panic disorders and social phobia' (Schifano et al., 1998p85). One limitation of most previous research, is that is difficult to gauge whether these adverse reactions are typical or atypical. Given the large number of recreational drug users (Saunders 1995; Webb et al., 1996), individual case studies may be describing rare or unusual adverse reactions. However, our recreational drug users were not selected because they had complained of any drug-related problems. This suggests that their adverse SCL-90 profiles (Table 2), are probably not atypical in those who have taken large quantities of ecstasy. Schifano et al. (1998) noted that $53 \%$ of the ecstasy users attending their drug clinic, were affected by one or more psychopathological problems. Moreover, those who reported problems had taken it frequently (median: 47 tablets); whereas those who did not report problems, had only taken it a few times (median: 3 MDMA tablets; Schifano et al., 1998). In the current study, our light ecstasy users differed significantly from the controls on just two SCL-90 scales: paranoid ideation and psychotisism. This could be taken to indicate that light ecstasy users suffer few psychiatric problems. However, they did produced intermediate values on most SCL-90 scales and this may be indicative of early problems, which might develop with continued drug use (Table 2). The question of how much ecstasy needs to be taken, before any problems develop, needs to be investigated by prospective studies. There is some empirical evidence for cognitive deficits in light MDMA users (Parrott et al., 1998; Parrott and Lasky, 1998). Schuster et al. (1998) assessed a random sample of 3000 German adolescents (14-25 years old), 3\% of whom had taken ecstasy, mostly on just a few occasions. Yet, despite comparatively light patterns of use, one-in-five of the ecstasy users reported MDMA-related problems, which were categorized as 'abuse or dependence'.

There are various possible explanations for these psychobiological problems. They may be direct consequence of repeated MDMA self-dosing upon serotonergic (5-HT) neurotransmission. In laboratory rats and monkeys, MDMA administration has been shown to produce long-lasting damage to serotonin pathways in the cerebral cortex and other brain areas (Ricaurte et al., 1992; Steele et al., 1994; Green et al., 1995). MDMA may also be neurotoxic in humans - the evidence for this was outlined earlier (Krystal et al., 1992; McCann et al., 1994, 1998; McCann et al., in press; Milani, 1997; Parrott and Lasky, 1998; Parrott et al., 1998; Parrott, in press). Serotonin is important for a wide variety of psychological functions: mood control, cognition, sleep, eating and sex. Thus if serotonin activity is being reduced by the repetitive use of MDMA, then a wide range of psychological functions might be affected. This could explain the broad range of factors being affected here (Table 2).

However, there are a number of alternative explanations. This study suffered from the same methodological limitations which characterize most research in this area. There was no random allocation of subjects to drug condition and it may be that only individuals with pre-existing problems decide to take ecstasy. In order to resolve this issue, prospective investigations are required. Another problem was that, although subjects were tested when drug-free, there was no control over recent drug consumption and this may have affected the findings. Another confounding factor was other illicit drug-use, with both groups of ecstasy users taking significantly more amphetamine, cocaine and LSD, than the controls (Table 1). The regular use of CNS stimulants and hallucinogens can lead to psychobiological problems: paranoid ideation, psychotic behaviour, pathological anxiety, cognitive difficulties and eating and sleeping disorders (Miller, 1985; Angrist, 1987; Schifano, 1996). Future studies could try to assess ecstasy users who have not taken other illicit drugs. However, this may be difficult, since most seem to use other psychoactive substances (Table 1). Schifano et al. (1998) noted that $95 \%$ of their ecstasy users took other illicit drugs, mainly cannabis and stimulants. Turner et al. (unpublished) found that $90 \%$ of their heavy ecstasy users smoked cannabis, while $82 \%$ took amphetamine. In the survey performed by Schuster et al. (1998) $97 \%$ of their novice ecstasy users had taken cannabis and $59 \%$ had taken cocaine. Verkes et al. (submitted for publication) controlled for some confounding factors by regression, but found it impossible to statistically control for cocaine consumption, because ecstasy and cocaine use were so highly correlated. Morgan (1998, 1999) attempted to resolve this problem by including a polydrug control group who had never used ecstasy, 
finding cognitive deficits and high impulsivity only in the ecstasy users (see below). This approach might be more widely followed, although highly selected groups may be atypical or unrepresentative.

Impulsivity was significantly higher in heavy ecstasy users compared to controls, whereas venturesomeness and empathy did not differ across groups (Table 2). High impulsivity has been noted in several previous studies of ecstasy users. Morgan (1998) administered the IVE questionnaire to three groups: recreational ecstasy users, polydrug users who had never taken ecstasy and controls who had never used illicit drugs. The ecstasy users reported significantly higher IVE impulsivity than both the other groups, whereas venturesomeness and empathy were similar across groups. Schifano et al. (1998) found DSM-11lR evidence for disordered impulse control, in some of their regular ecstasy users attending a drug dependency clinic. Turner et al. (unpublished) found increased IVE impulsivity and venturesomeness (but not empathy), in two groups of recreational ecstasy users compared to non user controls. But against these findings, McCann et al. (1994) found lower impulsivity in ecstasy users, which was against predictions (note: two impulsivity questionnaires were used; the other scale showed no group difference). Overall therefore, the current findings agree with Morgan, Schifano and Turner, in suggesting that regular ecstasy users display heightened impulsivity. This may be a reflection of reduced serotonin activity in the frontal cortex, since that is believed to underlie behavioural inhibition and impulse control (Hoyenga and Hoyenga, 1988). Alternatively, this impulsivity may simply be characteristic of young polydrug users. Uplifts, hassles, stresses and cognitive failures, did not differ significantly between groups. It had been hypothesized that ecstasy users might report higher rates of cognitive failure, since previous research has found cognitive deficits (Krystal et al., 1992; Parrott and Lasky, 1998; Parrott et al., 1998; Morgan, 1999). However, although the cognitive failure scores were highest in the heavy ecstasy user group, intermediate in light ecstasy users and lowest in the non users, these differences were non significant (Table 2). One limitation is that this scale relies upon self-awareness and drug users may be unaware of (or underestimate) their own cognitive deficits. Similar levels of uplifts, stresses and hassles, were reported by each group, indicating that their everyday life events were broadly equivalent. This provides a benchmark or positive internal control, against which the other psychobiological problems can be contrasted.

The current findings have a number of practical implications. Until recently, ecstasy had the reputation for being largely problem-free (Saunders, 1995), but it is becoming increasingly clear that this reputa- tion is unwarranted: 'Ecstasy is frequently perceived by users as a so-called 'safe drug', although this does not match the expert's view' (Schuster et al., 1998). Many psychopharmacologists would not be too surprised at the current findings (Table 2), since the regular use of amphetamine and/or cocaine can lead to various psychobiological problems (Miller, 1985; Angrist, 1987; Schifano, 1996; Morgan, 1999). The message that regular MDMA-use causes problems, needs to be incorporated into drug education packages. This information might also help those who develop psychiatric symptoms. At the moment, they may consider themselves unlucky or atypical and be afraid of seeking professional advice since their problems are self-inflicted (Parrott et al., 1998). Drug users should also be educated about the dangers of using high and frequent dosing. When ecstasy first became popular, most users took single tablets and allowed extended drug periods for neurochemical recovery (Parrott et al., 1998). However, in recent years this pattern has changed, with multiple-dosing and frequent consumption now more typical. It may be the intensity of self-dosing which is crucial for exhausting the serotonin system. There is no clear published evidence on this issue, although some empirical support is emerging in our latest neuropsychological study. Our working hypothesis is that high single MDMA doses may be particularly crucial for generating psychobiological problems. But it remains unclear whether MDMA alone is responsible, or whether they reflect the combined use of ecstasy with other stimulants/hallucinogens.

\section{References}

Angrist, B., 1987. Clinical effects of CNS stimulants: a selective update. In: Engel, J., Oreland, L. (Eds.), Brain Reward Systems and Abuse. Raven Press, New York.

Curran, H.V., Travill, R.A., 1997. Mood and cognitive effects of 3,4-methylenedioxymethamphetamine (MDMA, 'ecstasy'): weekend 'high' followed by mid-week 'low'. Addiction 92, 821-831.

Davison, D., Parrott, A.C., 1997. Ecstasy in recreational users: self-reported psychological and physiological effects. Hum. Psychopharmacol. 12, 91-97.

Derogatis, L.R., 1997. The SCL-90 Scoring Manual. Johns Hopkins School of Medicine, Clinical Psychometrics Unit.

Eysenck, H.J., Eysenck, S.B.G., 1991. The impulsiveness, venturesomeness and empathy scale. In: Eysenck Personality Scales. Hodder and Straughton, London.

Green, A.R., Cross, A.J., Goodwin, G.M., 1995. Review of the pharmacology and clinical pharmacology of 3,4-methylenedioxymethamphetamine (MDMA or ecstasy). Psychopharmacology $119,247-260$.

Hoyenga, K.B., Hoyenga, K.T., 1988. Psychobiology: The Neurone and Behaviour. Brooks-Cole, California.

Kokkevi, A., Stefanis, N., Anastasopoulou, E., Kostogianni, C., 1998. Personality disorders in drug abusers: prevalence and their association with AXIS 1 disorders as predictors of treatment retention. Addict. Behav. 23, 841-853. 
Krystal, J.H., Price, L.H., Opsahl, C., Ricaurte, G.A., Heninger, G.R., 1992. Chronic 3,4-methylenedioxymethamphetamine (MDMA) use: effects on mood and neuropsychological function? Am. J. Drug Alcohol Abuse 18, 331-341.

Milani, R., 1997. Distubi neuropsicologici assoiati all'uso di ecstasy. Dissertation. Faculty of Psychology, University of Padua.

Mc Cann, U.D., Eligulashvili, V., Ricaurte, G, in press. $(+-)$ 3,4-methylenedioxymethamphetamine (MDMA, 'ecstasy')-induced serotonin neurotoxicity: clinical studies. Neuropsychobiology.

McCann, U.D., Ricaurte, G., 1991. Lasting neuropsychiatric sequelae of $(+-)$ methylene-dioxymethamphetamine ('ecstasy') in recreational users. J. Clin. Psychopharmacol. 11, 302-305.

McCann, U.D., Ridenour, A., Shaham, Y., Ricaurte, G.A., 1994. Serotonin neurotoxicity after $(+-$ ) 3,4- methylenedioxymethamphetamine (MDMA; 'ecstasy'): a controlled study in humans. Neuropsychopharmacology 20, 129-138.

McCann, U.D., Slate, S.O., Ricaurte, G.A., 1996. Adverse reactions with 3,4-methylenedioxymethamphetamine (MDMA; 'ecstasy'). Drug Safety 15, 107-115.

McCann, U.D., Szabo, Z., Scheffel, U., Dannals, R.F., Ricaurte, G.A., 1998. Positron emission tomographic evidence of toxic effects of MDMA ('ecstasy') on brain serotonin neurones in human beings. Lancet 352, 1433-1437.

Miller, L., 1985. Neuropsychological assessment of substance abusers: review and recommendations. J. Subst. Abuse Treatment 2, 5-17.

Morgan, M.J., 1998. Lasting psychological sequelae of recreational use of MDMA (ecstasy): controlled studies in humans. J. Psychopharmacol. 12, 105-106.

Morgan, M.J., 1999. Memory deficits associated with recreational use of 'ecstasy' (MDMA). Psychopharmacology 141, 30-36.

Pallanti, S., Mazzi, D., 1992. MDMA (ecstasy) precipitation of panic disorder. Biol. Psychiat. 32, 91-95.

Parrott, A.C., 1998. The psychobiology of MDMA or 'ecstasy': symposium report. J. Psychopharmacol. 12, 97-102.

Parrott, A.C., in press. Human research on MDMA neurotoxicity: cognitive and behavioural indices of change. Neuropsychobiology.

Parrott, A.C., Kaye, F., 1999. Uplifts, hassles and cognitive failures, in cigarette smokers and non smokers. Behav. Pharmacol. 10 (in press).

Parrott, A.C., Lasky, J., 1998. Ecstasy (MDMA) effects upon mood and cognition; before, during and after a Saturday night dance. Psychopharmacology 139, 261-268.
Parrott, A.C., Lees, A., Garnham, N.J., Jones, M., Wesnes, K., 1998. Cognitive performance in recreational users of MDMA or 'ecstasy': evidence for memory deficits. J. Psychopharmacol. 12, 79-83.

Ricaurte, G.A., Martello, A.L., Katz, J.L., Martello, M.B., 1992. Lasting effects of 3,4- methylenedioxymethamphetamine (MDMA) on central serotonergic neurones in nonhuman primates: neurochemical observations. J. Pharmacol. Experiment Therapeut. 261, 616-622.

Ricaurte, G., Yuan, J., McCann, U.D., in press. (+ - ) 3,4methylenedioxymethamphetamine (MDMA, 'ecstasy')-induced serotonin neurotoxicity: studies in animals. Neuropsychobiology.

Saunders, N, 1995. Ecstasy and the Dance Culture. Neal's Yard Desktop Publishing, London.

Schifano, F., 1996. Cocaine misuse and dependence. Curr. Opin. Psychiat. 9, 225-230.

Schifano, F., Di Furia, L., Forza, G., Minicuci, N., Bricolo, R., 1998. MDMA ('ecstasy') consumption in the context of polydrug abuse: a report on 150 patients. Drug Alcohol Depend. 52, 85-90.

Schifano, F., Magni, G., 1994. MDMA (ecstasy) abuse: psychopathological features and craving for chocolate; a case series. Biol. Psychiat. 36, 763-767.

Schuster, P., Lieb, R., Lamertz, C., Wittchen, H.U., 1998. Is the use of ecstasy and hallucinogens increasing? Eur. Addict. Res. 4, $75-82$.

Series, H., Boeles, S., Dorkins, E., Peveler, R., 1994. Psychiatric complications of 'ecstasy' use. J. Psychopharmacol. 8, 60-61.

Solowij, N., Hall, W., Lee, N., 1992. Recreational MDMA use in Sydney: a profile of ecstasy users and their experiences with the drug. Br. J. Addiction 87, 1161-1172.

Steele, T.D., McCann, U.D., Ricaurte, G.A., 1994. 3,4-methylenedioxymethamphetamine (MDMA; 'ecstasy'): pharmacology and toxicology in animals and humans. Addiction 89, 539-551.

Turner, J.J.D., Nicolas, L., Parrott, A.C., 1998. Reduced calorie intake in the week following weekend MDMA (ecstasy) use. J. Psychopharmacol. 12, 36.

Turner, J.J.D., Arthur, I., Parrott, A.C., unpublished. Impulsivity, Venturesomeness and Psychopathology levels, in Recreational 'Ecstasy' (MDMA) Polydrug Users.

Verkes, R.J., Gissman, H.J., Pieters, M.S.M., Cohen, A.F., submitted for publication. Impairment of cognitive performance and serotonergic function in users of 'ecstasy'.

Webb, E., Ashton, C.H., Kelly, P., Kamali, F., 1996. Alcohol and drug use in UK university students. Lancet 348, 922-925. 